\section{Food safety and sustainable nutrition workshops: educational experiences for primary school children in Turin, Italy}

\author{
Amaranta Traversa, ${ }^{1}$ Daniela Adriano, ${ }^{1}$ \\ Alberto Bellio, ${ }^{1}$ \\ Daniela Manila Bianchi, ${ }^{1}$ \\ Silvia Gallina, ${ }^{1}$ Clara Ippolito, ${ }^{1}$ \\ Angelo Romano, ${ }^{1}$ Paola Durelli, ${ }^{2}$ \\ Andrea Pezzana, ${ }^{2}$ Lucia Decastelli ${ }^{1}$ \\ ${ }^{1}$ Food Control and Production Hygiene \\ Unit, Institute for Experimental \\ Veterinary Medicine of Piedmont, \\ Liguria and Aosta Valley, Turin; \\ ${ }^{2}$ Dietetics and Clinical Nutrition Unit, \\ San Giovanni Bosco Hospital, Turin, \\ Italy
}

\section{Abstract}

European control and prevention policies are focused to guarantee a high level of protection of consumers' health. Foodborne diseases as obesity, diabetes, food allergy, and food-borne outbreaks are increasing. To prevent food-borne diseases, it is fundamental to involve consumers, in particular children, in educational experiences aimed to learn the proper behaviours to be applied. In this context, we designed and performed 5 educational workshops about food safety, hidden allergens in food and nutrition aimed to involve children attending primary and summer school. These experiences let us collect observations about children knowledge and behaviours. From May to October 2015, a total of 1708 children aged 6 to 11 years joined our workshops. Children were involved in listening activities, laboratory experiments, handling games and sensory experiences. All participants were familiar with food allergy and were interested to know how to behave with allergic people. Children showed great curiosity in discovering that many foods normally contain live bacteria. Less than $25 \%$ of children reported to skip breakfast, to have it watching TV or to spend few minutes for it. Many of them $(>75 \%)$ thought that fruits and vegetables are all year-round available and are not related to a specific period. Very few participants $(<25 \%)$ knew that freezing is the treatment to be applied to make fresh fish safe from parasites. Children involved in food safety and nutrition educational experiences have the opportunity to increase their awareness about the correct behav- iours to prevent food-borne diseases and to improve their own critical thinking about food consumption.

\section{Introduction}

A high level of protection of consumer health is one of the fundamental objectives of the prevention and control policies in Europe. Food allergies, obesity, and diabetes are increasing. Around $8 \%$ of children suffer from food allergy, worldwide (Sicherer, 2014). In 2014, about 422 million people in the world had diabetes with a prevalence of $8.5 \%$ among the adult population (World Health Organization, 2016). Moreover, the domestic kitchen was the most commonly reported setting in the strong-evidence food-borne outbreaks in Europe (European Food Safety Authority, 2015). Consumer's education may be an important tool in preventing food related diseases as diabetes, obesity, and foodborne outbreaks. The majority of people with diabetes are affected by type 2 diabetes: exercising regularly and eating healthily are effective approaches available to prevent overweight, obesity and this type of diabetes (World Health Organization, 2016). Meanwhile, educational programmes about the proper behaviours to apply during handling and cooking foods are a useful way to involve consumers, to discourage incorrect practices at home that may drive to food poisoning, and to prevent cross-contamination with allergenic food. To prevent food-borne diseases, is fundamental to involve children, as future consumers, in educational experiences aimed to learn the proper behaviours to be applied. Children who become aware about the good food safety practices experiencing hands-on activities may help: they are more likely to perform long-term protective behaviours and may disseminate knowledge to their families (Losasso et al., 2014).

Here we describe the activities we performed and the results obtained from tutors' observational activities during our workshops aimed to engage primary school children to join educational experiences about food safety, food allergies and nutrition. These activities were included in the EXPO 2015 events host by the municipality of Turin.

\section{Materials and Methods}

From May to October 2015 we proposed five educational workshops dedicated to primary and summer schools. Each work-
Correspondence: Lucia Decastelli, Food Control and Production Hygiene Unit, Institute for Experimental Veterinary Medicine of Piedmont, Liguria and Aosta Valley, via Bologna 148, Turin, Italy.

Tel: +39.011.2686240

E-mail: lucia.decastelli@izsto.it

Key words: Children; Food safety; Nutrition; Education.

Conflict of interest: the authors declare no potential conflict of interest.

Funding: this project was realised thanks to the support of Compagnia di San Paolo.

Acknowledgments: the authors would like to thank Sara Astegiano, Monica Dalla Mutta, Grazia Rosaria Gariano, Guerrino Macori, Giuseppina Marello, Barbara Strambaci and Walter Vencia for helping during the workshops activities.

Received for publication: 19 July 2016.

Revision received: 30 November 2016.

Accepted for publication: 7 December 2016.

This work is licensed under a Creative Commons Attribution-NonCommercial 4.0 International License (CC BY-NC 4.0).

(C) Copyright A. Traversa et al., 2017

Licensee PAGEPress, Italy

Italian Journal of Food Safety 2017; 6:6177 doi:10.4081/ijfs.2017.6177

shop was designed to be performed by 1 tutor and 3 observers. They followed participants and observed children's replies to the questions and practical activities proposed during the workshops. The resulting observations were collected and reported in this paper. The workshops lasted 90 minutes, were structured to engage maximum 35 participants at a time and to offer an educational experience to a large number of participants (4 replications per day $/ 5$ days per week) and were designed as follows.

\section{Allergen hunt}

Welcome by telling the story The fairy tale about Sabrina who discovers to be allergic to hazelnut and learns how to manage her allergy. Presentation of the main allergenic foods: milk, eggs, wheat, nuts, soybeans, sesame seeds, crustaceans, molluscs, fish, peach, and kiwifruit.

Guess the allergen here inside: children had to select the right allergen-card that can be hidden in some proposed foods (eggs in hamburger; milk in ham; eggs in agedcheeses; nuts in snacks; cereal flour in Russian salad).

Special cookies: children were divided in two groups: group A cooked hazelnut 
cookies (using play dough and green glitter powder as hazelnut flour) and group B cooked coconut cookies (using play dough and gold glitter powder as coconut flour); then few cooks of group A went to help group $\mathrm{B}$ and vice versa. Dissemination of rules about how to behave with allergenic food and to prevent cross-contaminations.

\section{The good and the ugly: meet the bacteria in food}

Microorganisms: who are they?: children were involved in learning the different size of microorganisms (parasites, yeasts, moulds, bacteria, and viruses) and how we can see them (with our eyes, under the microscope or in cell culture) watching parasites directly found in food, images of bacteria under the microscope, and bacterial colonies grew on culture media.

Meet the good: children had to look the yeast and sugar experiment: what happens when you put yeast, sugar and warm water in a bottle and cover the bottle with a baloon. Then, children joined a question and answer game about the microorganisms present in milk, yoghurt, and cheeses (gorgonzola, brie, emmentaler, stracchino): they had to answer the question by raising the hand with the coloured card corresponding to the correct food.

Know the ugly: presentation of some pathogenic parasites and microorganisms (Anisakis, Salmonella, Staphylococcus aureus) that can contaminate food and cause diseases. Children had to see what happens when we handle a rubber chicken on a cutting board (with gold glitter powder mimicking Salmonella) and then cook it. Dissemination of rules on the correct behaviours to manage food at home: good handling, good cooking, and good storage.

\section{I love breakfast}

Children were divided into four random homogeneous groups and were involved in the following experiences. Presentation of the properties of breakfast.

Build your ideal breakfast: they had to choose images with food, to build the ideal savoury and sweet breakfast and to present it to the other groups. Description of the features of a healthy breakfast and the importance of having breakfast.

Sensory experiences: they have to use their senses to recognize and learn about some proposed food: watching and smelling milk-based drinks (cow, goat, soy and rice milk), watching and describing cereals, touching and guessing seasonal fruits, and watching and describing sugars (granulated sugar, brown sugar, honey, sweeteners, stevia). Description of the nutritional properties of the foods included in the activities. Projection of video about obesity in animals

\section{Batterikit: walking in the footsteps of the mysterious bacteria}

Children, as small scientific detectives, have to overcome tests to identify the bacteria that cause a food-borne outbreak on a school trip. They were divided in three random homogeneous groups and were involved in the following activities.

Let's discover the biofilm: using water sprays to wash away bacteria (glitter powder) from some set up surfaces. This handson activity let children know what happens whether bacteria produce biofilm or not (inspired by Marlow et al., 2013).

What's the shape of bacteria?: counting the number of bacteria with coccoid, rod or spiral form respectively mimicked by anellini, risoni and sorprese pasta (Figure 1). Children have to count the different types of pasta present in Petri plates.

Let's go to the kitchen: as small cooks, they had to prepare some food dishes, like cooked chicken, tomato salad and sandwich using wooden and textile food toys where glitter powder mimicked the potential bacteria load. Dissemination of the main rules to prevent bacterial cross-contaminations between surfaces, hands, and food.

The evidence of the tests (biofilm production, bacteria shape and the food involved) will help the children discover which bacteria ( $S$. aureus, Campylobacter or shiga toxin producing $E$. coli) caused the food-borne outbreak

\section{Stay healthy with fruits and veggies \\ Children were divided into four random}

homogeneous groups and were involved in the following activities. Presentation of the nutritional properties of fruits and vegetables hidden behind the different colours of these foods.

Seasonal fruits and veggies: each group of children had to fill in a list of the fruits and vegetables that can be found in a specific season. Dissemination of information about the seasonal productions.

Guess the legumes: each group had to recognize and learn about some legumes using their own sight and touch.

Where does it come from?: children had to link some food card to their origin Country cards: they had to choose the card depicting the right Country where some selected foods originally come from.

Touch and guess: children had to put their hands into a sealed box and to guess seasonal vegetables.

Smell and guess: children had to recognize some aromatic herbs contained in cotton balls.

Dissemination of the nutritional properties of the food proposed during the listed above experiences.

\section{Data collection}

During the workshops, tutor was driving children in the activities while the observers were collecting children's replies to the activities, to the questions and the games proposed. The percentage of correct answers (by a show of hands, written or oral answers, correct behaviours), the approval ratings and the behaviours (request of infor-

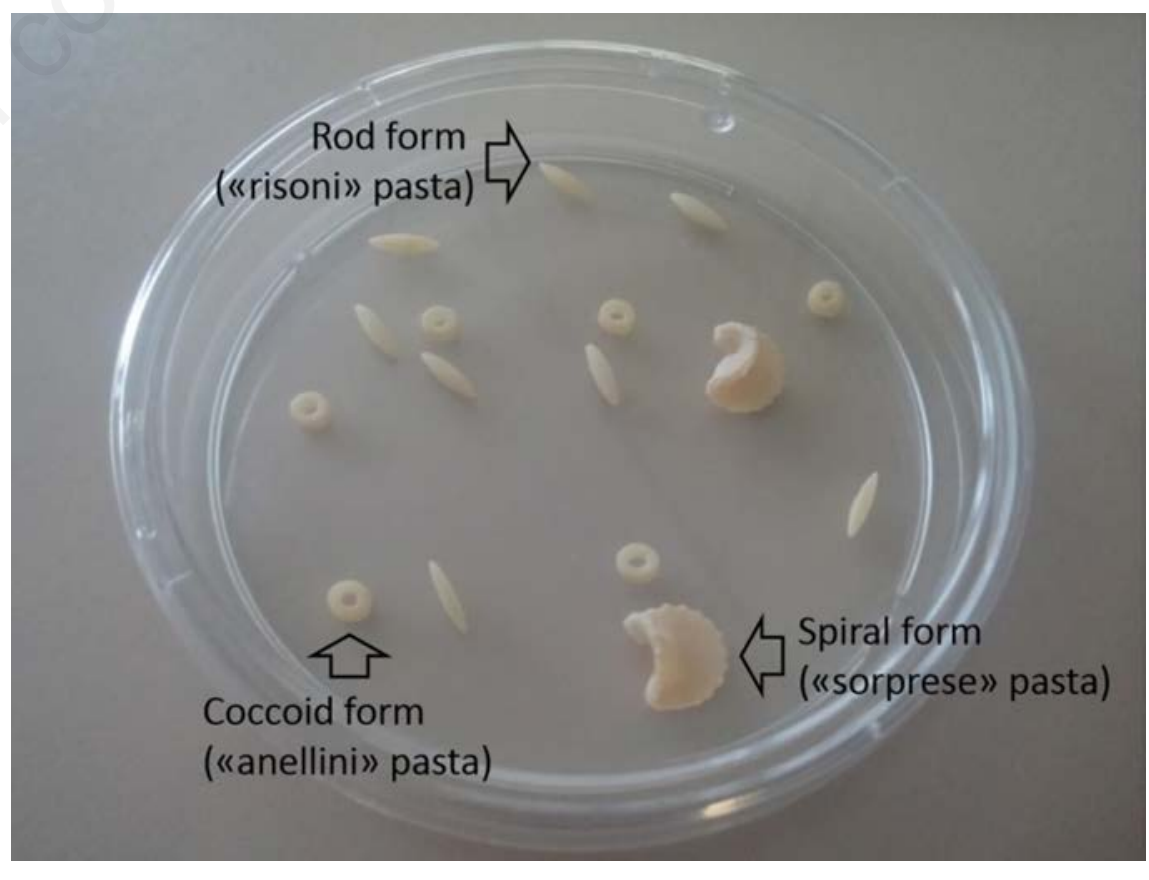

Figure 1. Pasta types used during the study. 
mation/queries, comments, and interest/lack of interest behaviours) were individually recorded by each observer. They were required to give a score (nobody $/ 0 \%$, few $/<25 \%$, half $/ 50 \%$, many $/>75 \%$, all $/ 100 \%)$ to children's responses and to note it. This paper reports the results showing inter-observer agreement.

\section{Results}

A total of 1708 children between 6 and 11 years joined the workshops, $61 \%$ belonging to primary schools and $39 \%$ to summer schools of Turin. The distribution of participants to each workshop by school class/age is reported in Table 1. The main results dealing with the five workshops previous described are reported below.

\section{Allergen hunt}

From $11^{\text {th }}$ to $15^{\text {th }}$ May 2015 ten classes of primary schools ( 216 children) joined the workshops. To the question if they have ever heard of the term allergy and which kind of food allergen did they know, all of them $(100 \%)$ showed to know the word allergy for environmental allergens, and many of them $(>75 \%)$ had already heard about milk, peach and hazelnut as food allergens. As expected, younger classes showed great interest $(>75 \%)$ in taking part the Special cookies handling game. Guess the allergen here inside did unexpectedly excite all participants, regardless of their age: most of them $(>75 \%)$ answered correctly and were aware about the presence of milk in ham and eggs in hamburgers.

\section{The good and the ugly: meet the bacteria in food}

From $18^{\text {th }}$ to $22^{\text {nd }}$ May 2015,18 classes of primary schools (380 children) joined the workshops. Few of them $(<25 \%)$ knew the word microorganisms but all participants $(100 \%)$ connected this word to very small life forms and showed to recognize the words moulds and bacteria. Some children $(<25 \%)$ associated moulds to the contamination in wet environments and many of them $(>75 \%)$ connected the words bacteria and virus with some human diseases. Many participants $(>75 \%)$ knew that we need a tool to see the bacteria, but less than $25 \%$ knew what viruses are and how we can see their presence. A good percentage $(>75 \%)$ of children answered correctly to the question and answer game about microorganisms in milk and in dairy products: they knew that Gorgonzola and Brie are made with moulds, as they are easily identifiable; participants correctly selected yoghurt and cheeses as dairy products where lactic bacteria are still alive, but few of them $(<25 \%)$ included milk. Children were surprised in discovering how bacteria (mimed by glitter powder) may be transferred from food to cooking surfaces and tools and may contaminate cooks' hands or other foods, especially ready-to eat foods as fresh salads or fruit. The majority $(>75 \%)$ knew that cooking kills microorganisms as bacteria, viruses, parasites, and yeasts. Very few participants $(<25 \%)$ knew that freezing is the treatment to be applied to make fresh fish safe from parasites.

\section{I love breakfast}

From $6^{\text {th }}$ to $10^{\text {th }}$ July 2015,19 groups of summer schools, a total of 374 children between 6 and 11 years, joined the workshops. Some children $(<25 \%)$ did not have breakfast, had it alone or watching the TV. Many of them (>75\%) ate only sweet breakfast without varying the foods consumed every day. The good majority $(>75 \%)$ built their ideal breakfast choosing images of hamburgers, hot dogs, pizza, chips, and sodas. Less than $25 \%$ of participants mentioned their healthy breakfast and showed to know products as stevia.

All the participants $(100 \%)$ enjoyed with enthusiasm the sensory experiences: all $(100 \%)$ correctly identified cow and goat milk and many of them $(>75 \%)$ recognized soy and rice milk. Children $(100 \%)$ guessed successfully the seasonal products in the box but the majority $(>75 \%)$ had some difficulties to identify cereals and sugars except for the most common as rice, grain, granulated sugar, and honey.

\section{Batterikit: walking in the footsteps of the mysterious bacteria}

From $30^{\text {th }}$ August to $4^{\text {th }}$ September 2015, 11 groups of summer schools, a total of 285 children between 6 and 11 years, joined the workshops. All children (100\%) were enthusiastic to enjoy the three practical activities we proposed. In the biofilm production trial, all of them realized in a practical and simple way the advantage that the bacteria may have with the production of biofilms: if biofilm (hair gel) is present on the surface water is not able to wash away bacteria (powder glitter). Counting the different shapes of bacteria, we were able to transmit to participants that bacteria may have different shapes, and that we can use their characteristics to distinguish and identify them. In the shoes of small cooks, children realised that under-cooked chicken, badly washed tomato salad or sandwich prepared without good hygienic practices may cause disease.

\section{Stay healthy with fruits and veggies}

From $19^{\text {th }}$ to $23^{\text {rd }}$ October 2015,20 classes of primary schools (453 children) joined the workshops. Many of them $(>75 \%)$ thought that fruits and vegetables are all year-round available and are not related to a specific period. Moreover, some children $(<25 \%)$ did not know where the food products were from. All the participants $(100 \%)$ guessed successfully the seasonal products in the box. The majority $(>75 \%)$ showed difficulties to recognise the aromatics herbs using their own smell; many of them associated the smell to some specific foods (chives and soup; ice pop and mint).

\section{Discussion}

We presented the most frequent food allergens (milk, eggs, wheat, nuts, soybeans, crustaceans, molluscs, fish, sesame seeds) among the ones reported by EU Regulation 1169/2011; we chose to add peach and kiwifruit to the list, because they are usually eaten by children and may cross-react with environmental allergens

Table 1. Distribution of the participants by school class/age.

\begin{tabular}{|c|c|c|c|c|c|c|}
\hline Workshop & $\begin{array}{l}1^{\text {st }} \text { class } \\
(6-7 \text { years })\end{array}$ & $\begin{array}{l}2^{\text {nd }} \text { class } \\
\text { (7-8 years) }\end{array}$ & $\begin{array}{l}3^{\text {rd }} \text { class } \\
(8-9 \text { years })\end{array}$ & $\begin{array}{c}4^{\text {th }} \text { class } \\
\text { ( } 9-10 \text { years) }\end{array}$ & $\begin{array}{c}5^{\text {th }} \text { class } \\
\text { (10-11 years) }\end{array}$ & Total \\
\hline Allergen hunt & $64(29.6)$ & $87(40.3)$ & $40(18.5)$ & $0(0)$ & $25(6.6)$ & $216(12.6)$ \\
\hline The good and the ugly & $96(25.3)$ & 85 (22.4) & $105(27.6)$ & $69(18.2)$ & $25(6.6)$ & $380(22.3)$ \\
\hline I love breakfast* & - & - & - & - & - & $374(21.9)$ \\
\hline Batterikit* & - & - & - & - & - & 285 (16.7) \\
\hline Stay healthy & $22(4.9)$ & $180(39.7)$ & $44(9.7)$ & $151(33.3)$ & $56(12.4)$ & $453(26.5)$ \\
\hline Total participants & & & & & & $1708(100)$ \\
\hline
\end{tabular}

*These workshops were dedicated to summer schools: participants are children between 6 and 11 years, more specific data about school class/age are not available. Values are reported as n (\%). 
(Cadoni et al., 2007). More than $75 \%$ of participants had already heard about food allergen and were interested in learning more about food allergens and in joining the practical experiences we proposed. The majority of children, especially from younger classes, were often competent, sensitive to food allergy and interested to know how to behave with allergic people that they often meet among relatives and friends. This workshop let children focus on the importance for allergic people of reading labels and checking restaurant menus, as some foods may contain unexpected food allergens.

Few participants knew the word microorganisms but almost all showed to recognize the words moulds and bacteria: children seemed to know the microorganisms that they probably heard about during their daily life. Few participants were aware about food contamination by microorganisms: children were surprised in discovering how bacteria may be transferred from food to cooking surfaces and tools and may contaminate cooks' hands or other foods. The majority of children showed great curiosity in discovering that milk normally contains live bacteria and dairy products may contain live moulds. The workshop was a useful opportunity for participants to learn more about some microorganism-based productions as bread and dairy products, to realize how to prevent food contamination by pathogenic microorganisms and to focus on the importance of a proper hand washing and good hygiene practices.

Breakfast should be healthy, appropriate and varied (Benton et al., 2001). Breakfast is an excellent occasion to eat together as a family avoiding distractions (TV) and it should take at least 10 minutes (Giovannini et al., 2008). Less than 25\% of children reported to skip breakfast, to have it watching TV, or in a hurry. Skipping breakfast or eating an inappropriate breakfast leads to less concentration, less memory and poor academic performances (Astbury et al., 2011). During workshops children learnt more about the different food they can eat at breakfast, discovered some new products, as cereals and sugars, and realized that they can consume savoury and sweet food varying their breakfast everyday. Many of them were oriented to inappropriate behaviours as hamburger and hot dogs consuming or breakfast skipping, but a smaller portion of participants mentioned their healthy breakfast and showed to know products as stevia. The projection of the videos was useful to communicate to participants in a funny way, even if transferred to animal world, the consequences of obesity.

In the food-borne investigations workshop, children focused on the importance of good hygiene practices as proper hand washing before preparing or eating foods, they realize that a good cooking allows the inactivation of foodborne bacteria, and that a good washing is necessary before eating raw vegetables.

The workshops were a useful opportunity for children to understand that fruits and vegetables are seasonal food that taste best when eaten in their season because they are freshly harvested: for many participants, fruits and vegetables are all yearround available and are not related to a specific period. Eating seasonally also benefits the environment: children realized that foods often come from far countries and focused their attention on the environmental damage which comes with shipping foods across large distances. Moreover, eating fruits and vegetables in the right season and varying the colours in our meals gives us all the vitamins, minerals, and antioxidants that our body needs. The participants showed difficulties to recognize the aromatic herbs, but they guessed correctly the seasonal fruit and vegetables in the box: children were less familiar with using their own smell but were competent in the use of their own touch sense.

\section{Conclusions}

Children joined with enthusiasm the practical experiences we proposed during the workshops. Participants were often competent, sensitive to food allergy topic and interested to know the rules to deal with food allergies and to reduce contamination during food handling and preparation. During food microbiology workshops, we tried to intrigue children about the microbes' world and to let them understand that incorrect behaviours may cause food contamination. Children were curious to discover and learn more about the food involved in nutrition workshops: participants focused their attention on the importance of having healthy breakfast, eating seasonal fruits and vegetables, varying their diet, and eating coloured food.

Children involved in food safety and nutrition educational experiences have the opportunity to increase their awareness about the correct behaviours to prevent food-borne diseases and food disorders and to improve their own critical thinking about food consumption.

\section{References}

Astbury NM, Taylor MA, Macdonald IA, 2011. Breakfast consumption affects appetite, energy intake, and the metabolic and endocrine responses to foods consumed later in the day in male habitual breakfast eaters. J Nutr 141:1381-9.

Benton D, Slater O, Donohoe RT, 2001. The influence of breakfast and a snack on psychological functioning. Physiol Behav 74:559-71.

Cadoni S, Ruffelli M, Fusari S, De Pit O, 2007. Oral allergic syndrome and recombinant allergens $\mathrm{rBet} \mathrm{V} 1$ AND rBet V 2. Eur J Inflam 5:21-5.

European Food Safety Authority, 2015. The European Union summary report on trends and sources of zoonoses, zoonotic agents and food-borne outbreaks in 2013. EFSA J 13:3991.

Losasso C, Cappa V, Cibin V, Mantovani C, Costa N, Faccio E, Andrighetto I, Ricci A, 2014. Food safety and Hygiene Lessons in the primary school: implications for risk-reduction behaviour. Foodborne Pathog Dis 11:1.

Giovannini M, Verduci E, Scaglioni S, Salcatici E, Bonza M, Riva E, Agostoni C, 2008. Breakfast: a good habit, not a repetitive custom. $\mathrm{J}$ Int Med Res 36:613-24.

Marlow VL, MacLean T, Brown H, Kiley TB, Stanley-Wall NR, 2013. Blast a biofilm: a hands-on activity for school children and members of the public. J Microbiol Biol Edu 2013:252-4.

Sicherer SH, Sampson HA, 2014. Food allergy: epidemiology, pathogenesis, diagnosis, and treatment. J Allerg Clin Immunol 133:291-307.

World Health Organization, 2016. Global report on diabetes. World Health Organization, Geneva, Switzerland. 